\title{
METABOLIC STUDIES OF CHLORPROPAMIDE IN NORMAL MEN AND IN DIABETIC SUBJECTS*
}

\author{
Raymond E. Knauff, $\nmid$ Stefan S. Fajans, Eduardo Ramirez,$\ddagger$ \\ Jerome W. Conn \\ Metabolism Research Unit, Division of Endocrinology and Metabolism, Depariment of \\ Internal Medicine, Universily of Michigan Medical School, Ann Arbor, Mich.
}

We have conducted short-term and prolonged studies in normal men and in diabetic subjects to compare the physiological properties of chlorpropamide and tolbutamide. The primary objectives of the investigation were: first, to correlate the hypoglycemic effect with the serum sulfonylurea level for each compound; and, second, to compare the rates of disappearance of the two drugs from the blood. In addition, we performed metabolic balance studies in two normal men during the administration of chlorpropamide.

\section{Methods}

Serum sulfonylurea determinations. Serum concentrations of both chlorpropamide and tolbutamide were determined by the same analytical method. This method, developed by Toolan and Wagner for chlorpropamide, and described elsewhere in this monograph, was found to serve equally well for the determination of tolbutamide.

The performance of the method in this laboratory is summarized in TABLE 1.

Table 1

Performance of the Analytic Method in the Determination of Serum Chlorpropamide and Tolbutamide Concentrations

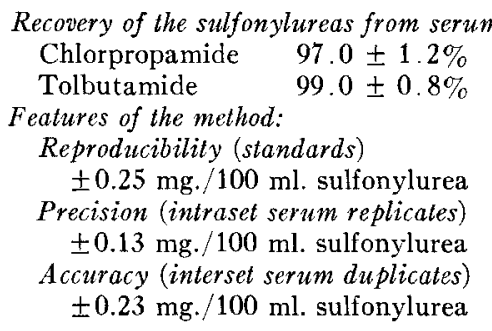

Values represent mean and/or standard deviation. The indicated values were derived as follows: recovery, 6 prepared serum samples each for chlorpropamide and tolbutamide between the concentrations of 0 to $24 \mathrm{mg} . / 100 \mathrm{ml}$; reproducibility, variation of the midlevel standard in 35 sets; precision, variation among 9 intraset serum replicates; accuracy, variation among 30 serum samples, as 15 duplicate pairs with concentrations of 1 to $35 \mathrm{mg} . / 100 \mathrm{ml}$., scattered among 13 sets.

The recovery of both sulfonylureas added to serum was essentially complete.

* The work reported in this paper was supported in part by Chas. Pfizer \& Co., Inc., Brooklyn, N. Y., and in part by Grant A-888 C3 from the National Institute of Arthritis and Metabolic Diseases, Public Health Service, Bethesda, Md.

$\dagger$ Investigator, the Howard Hughes Medical Institute, Miami Beach, Fla.

† Foreign Educational Fellow, Eli Lilly and Company, Indianapolis, Ind. 
The method, which showed excellent reproducibility, allowed a precision of approximately $0.1 \mathrm{mg}$. per cent and an accuracy of approximately $0.25 \mathrm{mg}$. per cent in serum measurements of sulfonylurea.

Additional data relevant to the application of the serum sulfonylurea method are provided in TABLE 2. Chlorpropamide and tolbutamide, as well as tolbutamide and the tolbutamide metabolite, are interrelated in terms of their relative absorbance intensity in the method. A low serum "blank" value was found.

TABLE 2

Data Relevant to the Application of the Serum Sulfonylukea Analytical Method Comparative quantitation data:

Chlorpropamide

Tolbutamide

Tolbutamide metabolite
Relative absorbancy

(on a weight basis)

100.0

$83.8 \quad 100.0$

83.8
$-\quad 38.5$

Serum "blank" values (55 different serum samples from 5 normal, 2 diabetic, and 2 other subjects; run in 22 sets):

$0.22 \pm 0.54 \mathrm{mg} . / 100 \mathrm{ml}$. (as chlorpropamide)

Method not corrupted by:

(1) Products from hemolysis

(2) Existence of the tolbutamide metabolite

Mean \pm standard deviation given for serum blank values.

The method is not corrupted by the products from hemolysis. Aliquots of 2 different blood samples devoid of sulfonylurea were briskly beaten with wooden applicators while the blood was clotting. The resultant deeply pigmented sera, when compared in analysis with nonhemolyzed "duplicates," were found to have increased in apparent sulfonylurea only by about $0.4 \mathrm{mg}$. per cent. The degree of hemolysis produced deliberately in this evaluation was approximately 10 times greater than any experienced throughout the investigation being described. Mention is made of this observation concerning hemolysis, since plasma and serum tolbutamide methods in current use have a demonstrated ${ }^{1}$ or likely ${ }^{2-4}$ sensitivity to corruption by the products from hemolysis.

As an important consideration, the sulfonylurea method used in our studies is not corrupted by the existence of the tolbutamide metabolite ${ }^{5}$ (1-butyl3-p-carboxyphenylsulfonylurea). The metabolic half life of the tolbutamide metabolite was determined by techniques similar to those described below for tolbutamide. It was found to be approximately 9 times (8.6) shorter than the metabolic half life of tolbutamide. The metabolite thus disappears from blood approximately 9 times faster than tolbutamide and exhibits absorbancy approximately $2 \frac{1}{2}$ times less than tolbutamide in this method (TABLE 2). It is unlikely, therefore, that measured serum sulfonylurea levels, after tolbutamide administration, could be more than about 4 per cent in error because of the presence of the metabolite.

Other determinations. Fasting blood glucose; serum sodium, potassium, and chloride; and urinary nitrogen, creatinine, sodium, potassium, chloride, 
17-hydroxycorticoids, and 17-ketosteroids were determined by methods previously used in this laboratory. ${ }^{6}$

Subjects. Two normal and 2 diabetic subjects were admitted to the Metabolism Research Laboratory and maintained on constant diets. The 2 normal subjects (R. R., male, age $23,70 \mathrm{~kg}$.; and J. D., male, age $20,69 \mathrm{~kg}$.) received a diet that provided $200 \mathrm{mEq}$. sodium, $113 \mathrm{mEq}$. potassium, $17.3 \mathrm{gm}$. nitrogen, $320 \mathrm{gm}$. carbohydrate, and 2900 calories per day. One diabetic patient (A. R., female, age 62, $87 \mathrm{~kg}$.) received $178 \mathrm{gm}$. carbohydrate and 2150 calories per day; the other (R. B., female, age $63,73 \mathrm{~kg}$.) received 150 $\mathrm{gm}$. carbohydrate and 1400 calories per day.

Eleven diabetic patients, chosen because they responded poorly to tolbutamide, were studied in the Endocrinology and Metabolism Out-Patient Clinic of the University Medical Center.

\section{Results}

The disappearance of chlorpropamide and tolbutamide from the blood. Measurements of chlorpropamide or tolbutamide disappearance from blood were made after intravenous administration of each compound. The series included observations on 2 normal and 2 diabetic subjects. After an overnight fast each subject received chlorpropamide or tolbutamide sodium* (30 mg. $/ \mathrm{kg}$.) at 8:00 A.M., and food was withheld for 6 hours.

Data for one of the normal subjects are presented in FIGURE 1 . It is seen that the chlorpropamide serum concentration declined from about $21 \mathrm{mg}$. per cent at $15 \mathrm{~min}$. to about $18 \mathrm{mg}$. per cent at 6 hours, whereas the tolbutamide serum concentration fell more rapidly from about $20 \mathrm{mg}$. per cent at $15 \mathrm{~min}$. to about $8 \mathrm{mg}$. per cent at 6 hours. The serum chlorpropamide concentration continued to decline slowly, and the serum tolbutamide concentration fell much more rapidly. The 2 drug levels extrapolated to zero concentration at 18 hours for tolbutamide and at 145 hours for chlorpropamide. Thus, under the circumstances of this experiment, tolbutamide disappeared from the blood approximately 8 times faster than chlorpropamide.

It is of interest to note (FIGURE 1) that there was no significant difference between the nature and degree of the acute hypoglycemia produced by the 2 drugs at this dosage level. Such was the case even though the tolbutamide serum concentration had fallen rapidly as compared with that of chlorpropamide. As would be anticipated, there was no correlation between the serum drug levels and the blood glucose levels in these acute (6-hour) experiments. It is likely that under these conditions hypoglycemia was maximally induced when the serum sulfonylurea levels (after the administration of either drug) were above $20 \mathrm{mg}$. per cent for $15 \mathrm{~min}$., $18 \mathrm{mg}$. per cent for $30 \mathrm{~min}$, or $17 \mathrm{mg}$. per cent for $45 \mathrm{~min}$. Reversal of the progressive hypoglycemia at about $45 \mathrm{~min}$. was undoubtedly the result of effective counteraction through physiological mechanisms that function to normalize the concentration of blood glucose.

FIGURE 2 shows data for one of the diabetic subjects. This subject had

* Chlorpropamide was supplied by I). Iezzoni, Chas. Pfizer \& Co., Inc. Tolbutamide was supplied by C. J. O'Donovan, The Upjohn Co., Kalamazoo, Mich. 


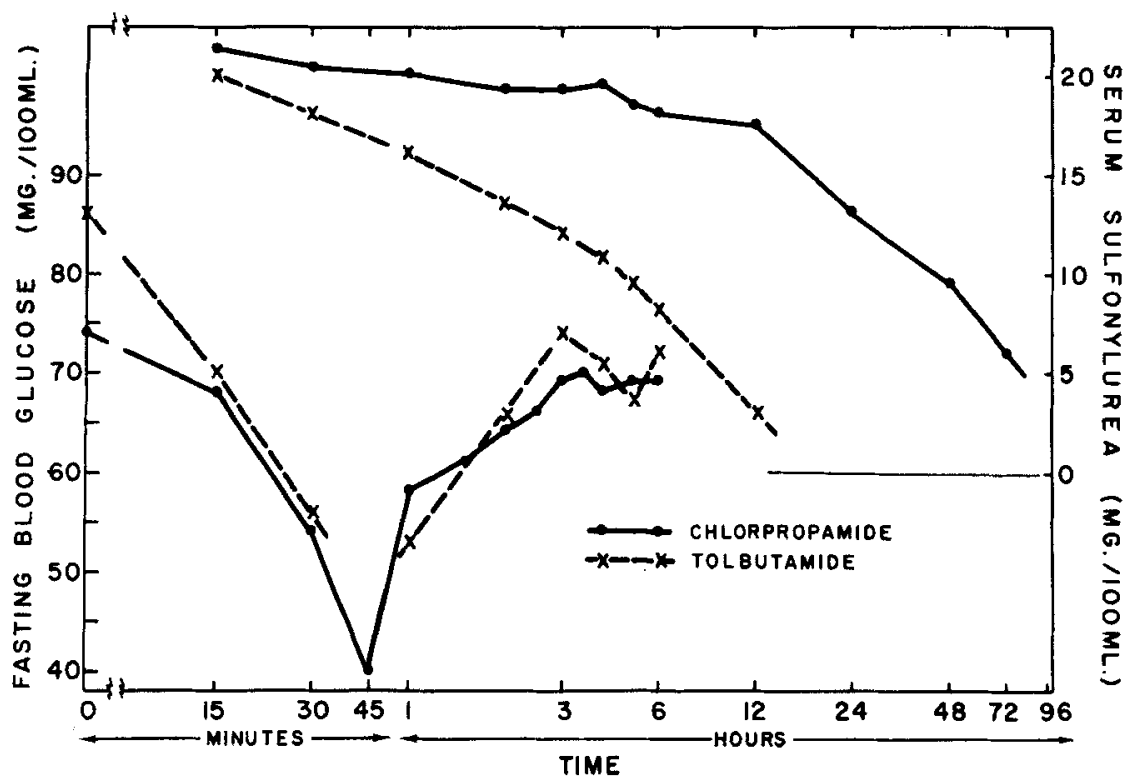

Figure 1. Serum sulfonylurea and fasting blood glucose levels after the intravenous administration of chlorpropamide and tolbutamide to a normal subject (J. D., male).

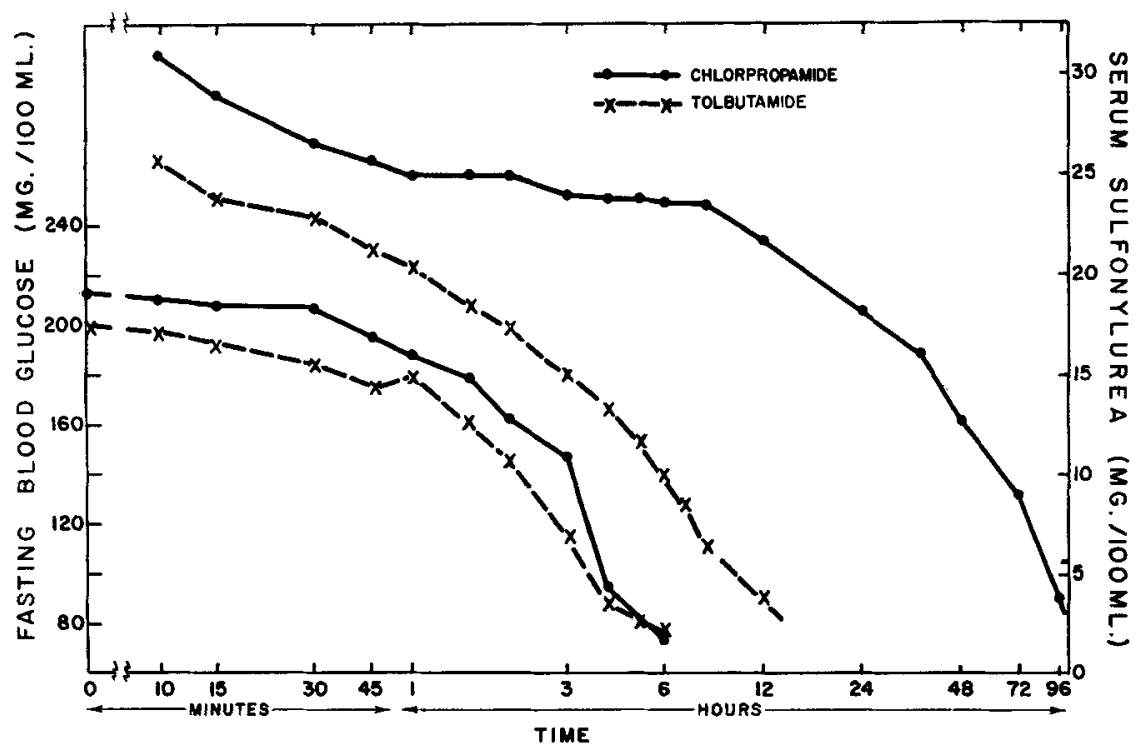

Figure 2. Serum sulfonylurea and fasting blood glucose levels after the intravenous administration of chlorpropamide and tolbutamide to a diabetic subject ( $A$. R., female). 
somewhat higher serum sulfonylurea levels during the study. The higher serum levels probably resulted from the fact that the dose administered was based upon gross body weight, and also from the fact that this subject was moderately obese. Another notable characteristic of the sulfonylurea disappearance curves, in this case, is the marked difference between the chlorpropamide and tolbutamide serum levels. Since the disappearance rates for the 2 drugs were very similar and quite constant during the interval from 10 through $60 \mathrm{~min}$., the early difference in serum concentrations probably reflects a difference in distribution space for the 2 drugs.

In spite of the higher serum levels and the initial differential between the curves, the disappearance rates for chlorpropamide and tolbutamide in this diabetic subject were quite similar to those for the previous normal subject (FIGURE 1). It should be noted that this diabetic subject, as well as the other one in the series, was previously treated with both sulfonylurea compounds. The administration of chlorpropamide to both diabetic subjects was discontinued 9 days before these studies began.

In the diabetic subject (FIGURE 2) there were almost identical progressive reductions in blood sugar after intravenous administration of equal quantities of the 2 drugs. It is impressive that these acute blood glucose responses were remarkably similar in spite of the great difference that had developed in the serum sulfonylurea concentrations by 6 hours. These results are consistent with those obtained in the normal subject, and they suggest that the pattern for the blood glucose response was determined at an early time when the serum sulfonylurea concentration for each compound was sufficiently high to induce a maximal response.

In the other 2 subjects, the second normal and the second diabetic, there was also no significant difference in the acute blood glucose responses after intravenous administration of the indicated amounts of chlorpropamide and tolbutamide. The sulfonylurea disappearance rates for both of these subjects were very similar to those already illustrated (FIGURES 1 and 2).

A more detailed graphic evaluation of the disappearance rates of chlorpropamide and tolbutamide was made for each of the 4 subjects. Such an evaluation is illustrated in FIGURE 3 for one of the diabetic subjects. The disappearance rate is expressed as metabolic half life ( $\left.t_{1 / 2}\right)$ which, conventionally, is defined as the time required for the serum concentration to decline to one half of a previous level.

It is seen that after chlorpropamide administration at zero time there accurs a very rapid decrease in the serum concentration during the first $10 \mathrm{~min}$. (first 2 dots, at 5 and $10 \mathrm{~min}$.). A rapid decline in serum concentration follows so that the metabolic half life of chlorpropamide during the time interval from 15 through $45 \mathrm{~min}$. is calculated to be 2.8 hours. At about the first hour the serum concentration of chlorpropamide stabilizes and remains essentially unchanged up to the sixth hour. During this 5 -hour period the half life of chlorpropamide is described, of course, as infinite. After this plateau phase, the half-life time fluctuates considerably until about 36 hours, when a terminal steady-state disappearance begins. During 
this phase of terminal steady-state disappearance (36 to 144 hours) chlorpropamide is calculated to have a metabolic half life of 35 to 36 hours.

The disappearance of tolbutamide (FIGURE 3), after its intravenous administration, can be described also in rate phases. The three indicated phases for tolbutamide represent half life times of 3.3,4.9, and 3.8 hours.

The phases which have been described in this subject for chlorpropamide and tolbutamide by half life calculations were also observed in the second diabetic and in both normal subjects. The simplest interpretation which can account for the phases observed after intravenous administration of each compound is: (1) an early (0 to $60 \mathrm{~min}$.) unstable space distribution; (2) a redistribution ( 1 to 36 hours for chlorpropamide, 1 to 6 hours for tolbutamide); and (3) a stable space distribution ( $>36$ hours for chlorpropamide,

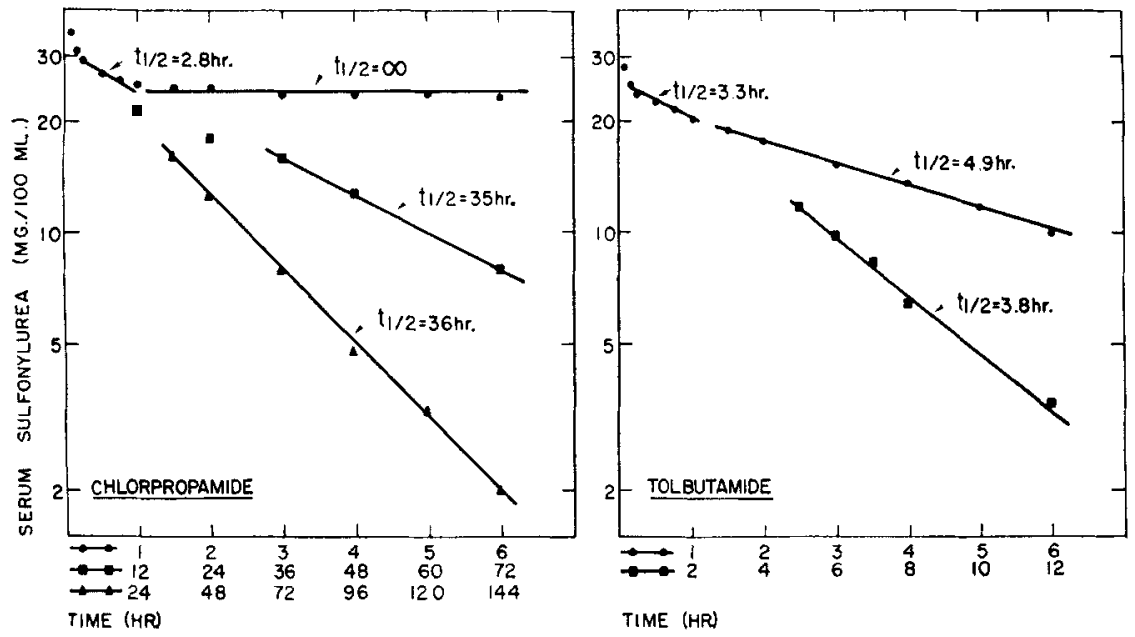

Figure 3. Metabolic half-life times for chlorpropamide and tolbutamide in a diabetic subject (A. R., female).

$>6$ hours for tolbutamide). It would be extremely interesting to make space-distribution calculations for strategic timings in such an experimental series as this. Since our studies did not extend to drug balance (excretory studies), this was not possible for these subjects. It was interesting, however, to make initial or zero-time calculations of space distribution in a comparison of the 2 drugs. Extrapolation from the 5 - and 10 -min. points, in the 2 diabetic subjects gave chlorpropamide space volumes of 7.6 and 6.91. and tolbutamide space volumes of 9.0 and $9.3 \mathrm{l}$. The mean chlorpropamide and tolbutamide spaces in these 2 diabetics were 9 and 11 per cent of body weight, respectively.

The difference between mean values of 7.3 and 9.21 . for chlorpropamide and tolbutamide spaces, respectively, would seem highly significant in these 2 subjects. From preliminary studies of deliberate blood sample hemolysis after chlorpropamide and tolbutamide administration it appears that the different space distributions of these 2 drugs may be explainable, to a major 
extent, on the basis of different concentrations in red cell water. The calculated zero-time distribution volumes are probably smaller than the equilibrium distribution volumes and are discussed here only because they point up a difference between the 2 drugs. On the basis of published data by Wick et $a l .^{7}$ for tolbutamide in the eviscerated and nephrectomized rabbit, the equilibrium tolbutamide space might be anticipated as 13 to 19 per cent of body weight in man. Zero-time distribution calculations have not been made for the 2 normal subjects, since 5- and 10-min. points on the sulfonylurea disappearance curves were not obtained.

TABLE 3

Metabolic Half-tife Measurements for Chlorpropamide and Tolbutamide in Two Normal and Two Diabetic Subjects

\begin{tabular}{|c|c|c|c|c|c|c|c|}
\hline \multirow{3}{*}{ Phase } & \multirow{3}{*}{$\begin{array}{c}\text { Time } \\
\text { interval } \\
\text { (hours) }\end{array}$} & \multicolumn{6}{|c|}{ Metabolic half-life time (hours) } \\
\hline & & \multicolumn{3}{|c|}{ Normal subject } & \multicolumn{3}{|c|}{ Diabetic subject } \\
\hline & & J. D. & R. R. & Mean \pm M. D. & A. R. & R. B. & Mean \pm M. D. \\
\hline \multicolumn{8}{|c|}{ Chlorpropamide } \\
\hline$A$ & $<1$ & 3.0 & 2.9 & $3.0 \pm 0.1$ & 2.8 & 2.8 & $2.8 \pm 0.0$ \\
\hline $\mathrm{B}$ & 1 to 6 & $\infty$ & $\infty$ & & $\infty$ & $\infty$ & \\
\hline C & 36 to 72 & 36 & 35 & 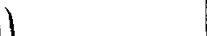 & 35 & 37 & \\
\hline & 72 to 120 & - & - & $35 \pm 1$ & 36 & 37 & $35 \pm 1$ \\
\hline Postoral & 24 to 120 & 35 & 34 & & 32 & - & \\
\hline \multicolumn{8}{|c|}{ Tolbutamide } \\
\hline A & $<1$ & 1.8 & 1.8 & $1.8 \pm 0.0$ & 3.3 & 2.6 & $3.0 \pm 0.4$ \\
\hline B & 1 to 6 & 5.1 & 6.1 & $5.6 \pm 0.5$ & 4.9 & 6.5 & $5.7 \pm 0.8$ \\
\hline $\mathrm{C}$ & 6 to 12 & 4.3 & 4.8 & $4.6 \pm 0.3$ & 3.8 & 5.8 & $4.8 \pm 1.0$ \\
\hline
\end{tabular}

Chlorpropamide/tolbutamide disapjearance ratio: Normal subjects, $35 / 4.6=7.6$; diabetic subjects, $35 / 4.8=7.3$.

The disappearance data for all 4 subjects in the series are summarized in TABLE 3 . A, B, and $\mathrm{C}$ represent the 3 phases previously described for intravenous chlorpropamide and tolbutamide in conjunction with FIGURE 3 . There are probably no significant differences in the metabolic half-life times between the 2 normal and the 2 diabetic subjects for any of the 3 phases with each of the drugs, with the possible exception of the tolbutamide phase A.

Half-life times calculated after the cessation of oral (postoral) chlorpropamide administration are given in TABLE 3 for 3 of the 4 subjects as well.

The phase $\mathrm{C}$ and postoral metabolic half-life times, which represent terminal steady-state disappearance and a wide range of serum concentrations, 
were used to arrive at a comparison of the rates of disappearance of these 2 drugs from the blood. This comparison is given as a ratio calculation below TABLE 3 and indicates that tolbutamide disappears from the blood from 7 to 8 times faster than chlorpropamide.

The relative potency of chlorpropamide and tolbutamide. It was clear that acute studies and classic dose-response studies would yield information of limited value in a potency comparison of chlorpropamide and tolbutamide, especially if one attempted to apply such information in terms of long-term oral therapy. On the other hand, it appeared as though meaningful data

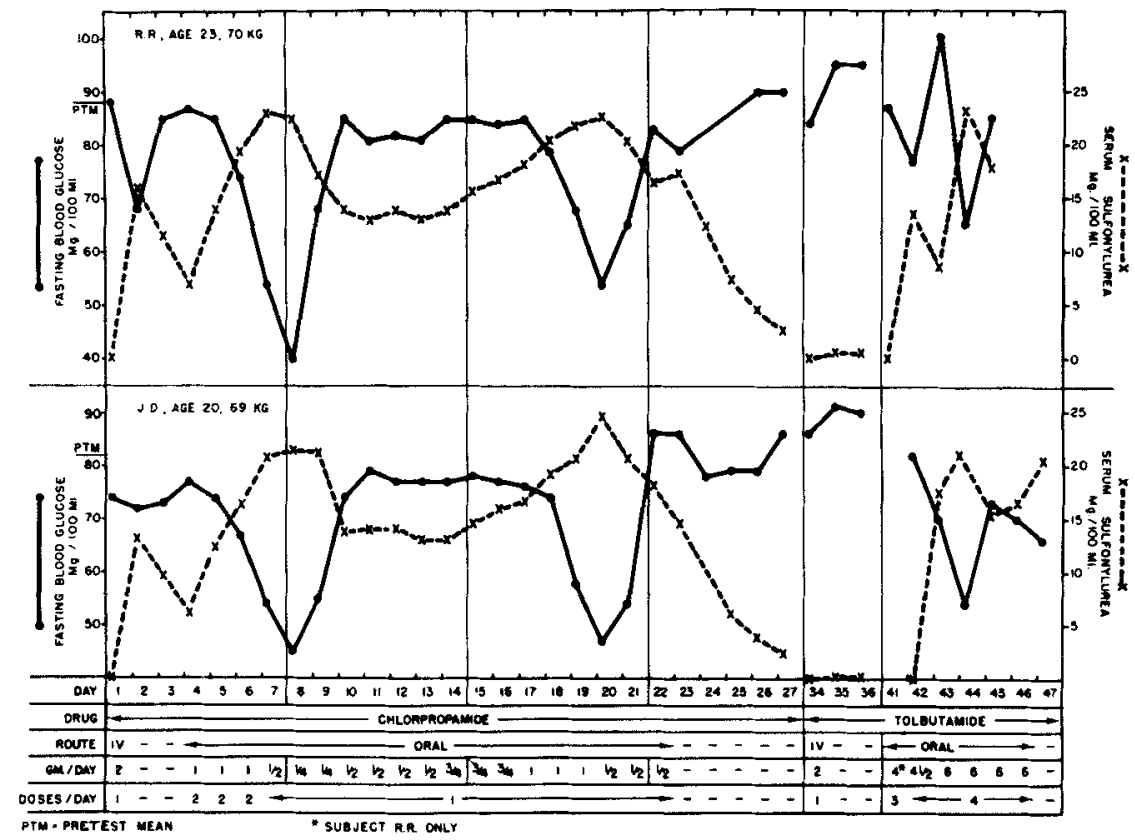

FIGURE 4. Fasting blood glucose and fasting serum sulfonylurea levels in 2 normal men during the administration of chlorpropamide and tolbutamide.

could be derived from long-term comparisons of the 2 drugs at various dosage levels and from a separation of the classic dose-response study into 2 distinct components: the relation of dose to drug blood level and the relation of drug blood level to blood glucose response. Such an approach would take into account the facts that: (1) the 2 drugs had markedly different half-life times, and (2) the 2 drugs probably had different spaces of distribution. With these considerations in mind, 2 normal men were studied for a period of about 4 weeks on an identical schedule of changing doses of oral chlorpropamide (FIGURE 4). During this period the men were carried through 2 cycles of symptomatic hypoglycemia. In a subsequent period they were observed during episodes of tolbutamide-induced hypoglycemia. Much larger oral dosages of tolbutamide (at least 6 times larger) were required to produce comparable hypoglycemia and comparable serum sul- 
Knauff et al.: Chlorpropamide in Normals and Diabetics 611

fonylurea levels. Daily measurements of the fasting blood glucose and the fasting serum sulfonylurea levels during oral administration of the 2 drugs revealed a consistent pattern.

In FIGURE 5 the fasting serum sulfonylurea levels are plotted against changes in the fasting blood glucose levels for the 2 normal men. Standard

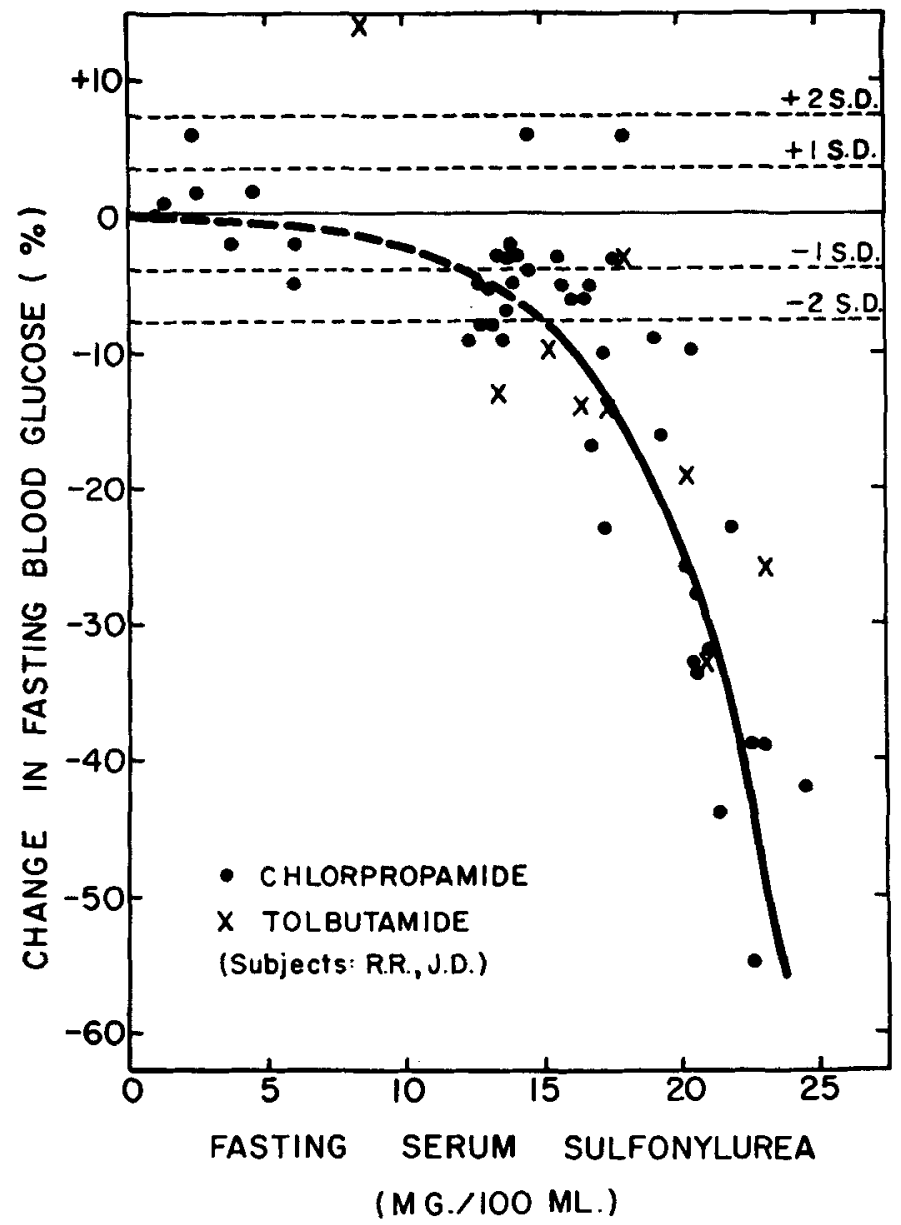

Figure 5. Correlation between change in fasting blood glucose and fasting serum sulfonylurea levels in 2 normal subjects.

deviations relate to both men for daily fasting blood glucose measurements during an 8-day pretest period. The curve was originally constructed in the absence of the tolbutamide points, with reference only to the chlorpropamide points. It is apparent, however, that when the tolbutamide points are included, as they are in this figure, they fit the previously constructed curve for chlorpropamide. These results indicate that, within the standardizations and extensiveness of these observations, chlorpropamide 
and tolbutamide are equally active, on the basis of serum concentrations, as agents to produce change in the blood glucose concentration.

A serum sulfonylurea level of about $12 \mathrm{mg}$. per cent was required to produce a decrease of 1 standard deviation in the fasting blood glucose in these normal men. A decrease of twice the standard deviation in the fasting blood glucose resulted from a serum sulfonylurea level of about $15 \mathrm{mg}$. per

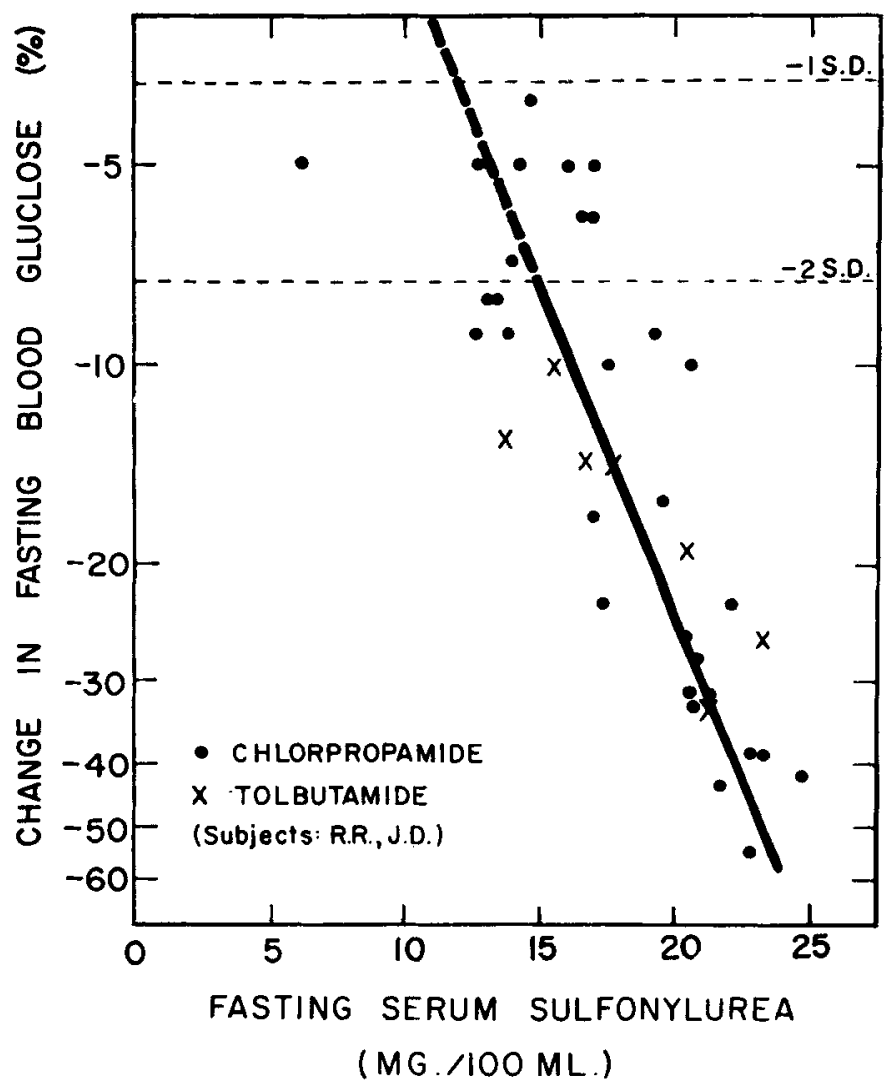

Figure. 6. Correlation between change in fasting blood glucose and fasting serum sulfonylurea levels in 2 normal subjects (semilogarithmic presentation).

cent. All sulfonylurea levels above $18.5 \mathrm{mg}$. per cent produced decreases in the fasting blood glucose of at least twice the standard deviation. Within the range of significant measurements, increments in serum sulfonylurea concentration of approximately $3 \mathrm{mg}$. per cent double the effect on the fasting blood glucose.

The data from FIGURE 5 are reproduced in FIGURE 6 with semilogarithmic coordinates. Under this circumstance the relationship between the fasting serum sulfonylurea level and the change in the fasting blood glucose is represented by a straight line. 
Since chlorpropamide and tolbutamide, on the basis of their serum concentrations, are approximately equally active, and since tolbutamide disappears from the blood approximately 8 times faster than chlorpropamide, it follows that chlorpropamide has the potentiality of being approximately 8 times more effective than tolbutamide, on a weight basis, when the 2 drugs are used as oral therapeutic agents.

It was of interest to obtain information on how the serum chlorpropamide concentration varies during a 24-hour period when 500 to $750 \mathrm{mg}$. is administered each morning with breakfast (TABLE 4). Although the 2 subjects had

TABLE 4

Variation of Serum Chlorpropamide Levels During the Day After Single Oral Morning Doses of the Drug in 2 Normal Men

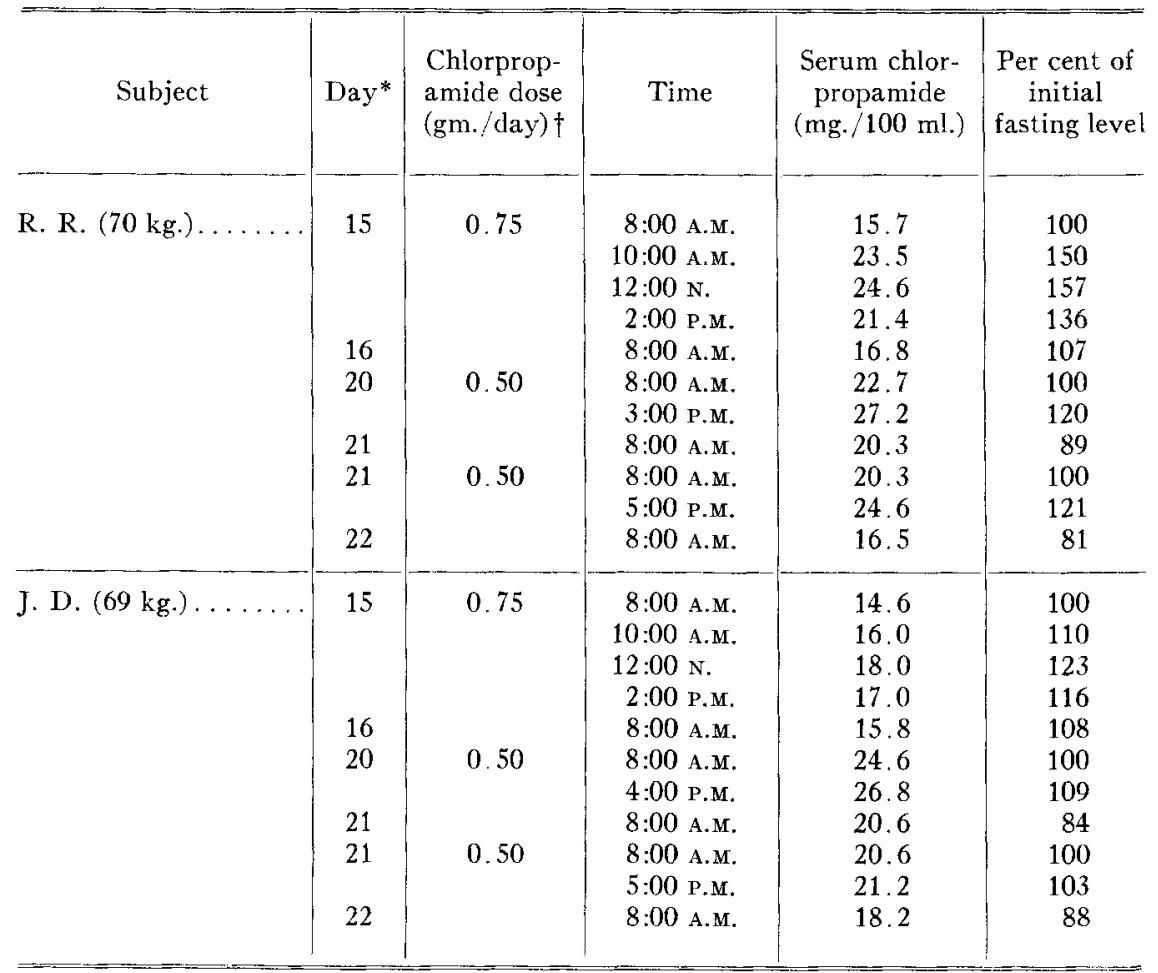

* Days correspond with those in FIGURE 4.

$\dagger$ Total dose taken shortly after 8:00 A.M. with breakfast.

very similar fasting serum chlorpropamide concentrations on the same drug dosages, they showed somewhat different but quite consistent variations in serum levels during the intervals studied. The subjects developed maximum serum chlorpropamide concentrations of 123 and 157 per cent of the fasting levels about 4 hours after an oral dose at 8:00 A.m. The serum levels at 5:00 P.M. were 103 and 121 per cent of the morning fasting levels even when there was a moderate decline in the fasting serum level the following morning. 
Thus, a single dose of chlorpropamide at 8:00 A.M. would seem to provide elevated serum sulfonylurea levels (that is, relative to the fasting level) during the absorptive portion of the day (about 8:00 A.M. to 8:00 P.M.) and to allow the serum level to decine to a near-fasting level early in the usually nonabsorptive portion (about 8:00 P.M. to 8:00 A.M.) of the day. This feature, which is provided by the long metabolic half-life time of chlorpropamide, may prove to be advantageous therapeutically.

Clinical sludies. Eleven diabetic patients who responded poorly to tolbutamide were treated with chlorpropamide. All responded better to chlorpropamide at considerably lower daily dosages in most cases.

The comparative response of the 11 diabetic patients to the 2 compounds is illustrated in TABLE 5. Each patient received each substance, at the indicated dosages, for at least 3 days and usually for 1 week prior to the determinations. Complete comparative data were obtained for the first 3 patients

TABLE 5

Comparative Response of Patients with Diabetes Mellitus to Oral Tolbutamide and Chlorpropamide Therairy

\begin{tabular}{|c|c|c|c|c|c|c|}
\hline \multirow[b]{2}{*}{ Patient } & \multicolumn{3}{|c|}{ Tolbutamide } & \multicolumn{3}{|c|}{ ChLorpropamide } \\
\hline & $\begin{array}{c}\text { Dosage } \\
\text { (gm./day) }\end{array}$ & $\begin{array}{c}\text { Fasting } \\
\text { blood } \\
\text { glucose } \\
\text { (mg. } / 100 \mathrm{ml} . \text { ) }\end{array}$ & $\begin{array}{c}\text { Fasting } \\
\text { serum } \\
\text { tolbutamide } \\
\text { (mg-/100 ml.) }\end{array}$ & $\begin{array}{c}\text { Dosage } \\
\text { (gm./day })\end{array}$ & $\begin{array}{c}\text { Fasting } \\
\text { blood } \\
\text { glucose } \\
\text { (mg./100 ml.) }\end{array}$ & $\begin{array}{c}\text { Fasting } \\
\text { serum } \\
\text { chlorpropamide } \\
\text { (mg. } / 100 \mathrm{ml} \text { ) }\end{array}$ \\
\hline A. R. $(95 \mathrm{~kg}$.$) .$ & 3.0 & 191 & 5.3 & 0.75 & 1.38 & 14.2 \\
\hline E. E. $(74 \mathrm{~kg}$.$) .$ & 1.5 & 183 & 6.1 & 0.5 & 86 & 19.5 \\
\hline $\mathrm{H}, \mathrm{H} .(60 \mathrm{~kg}$.$) .$ & 3.0 & 176 & 4.6 & 1.0 & 88 & 29.3 \\
\hline R. B. $(73 \mathrm{~kg}$.$) .$ & 2,0 & 150 & - & 1.0 & 1.36 & 22.0 \\
\hline A. C. $(58 \mathrm{~kg})$ & 2.0 & 210 & - & 2.0 & 146 & $\ldots$ \\
\hline F. F. $(5.5$ kg. $)$. & 2.0 & 168 & 一 & 1.0 & 131 & 16.1 \\
\hline K. H. $(72 \mathrm{~kg})$.. & 1.0 & 155 & - & 0.5 & 83 & 22.2 \\
\hline S. J. $(107 \mathrm{~kg})$.. & 3.0 & 227 & $\ldots$ & 1.5 & 155 & 36.3 \\
\hline M.R. $(88 \mathrm{~kg}$.$) .$ & 1. 5 & 153 & - & 0.5 & 109 & 10.2 \\
\hline P. S. $(41 \mathrm{~kg}$.$) .$ & 1.5 & 210 & - & 1.0 & 139 & 35.5 \\
\hline i. M. $(75 \mathrm{~kg})$. & 1.0 & 1.31 & - & 0.25 & 99 & 7.5 \\
\hline
\end{tabular}

listed. The decreases in the fasting blood glucose levels experienced by these 3 patients on the indicated tolbutamide dosages were slight. The relatively low fasting serum tolbutamide levels are to be noted. In the same 3 patients considerably lower dosages of chlorpropamide produced higher serum levels of the drug and, concurrently, more intense decreases of the fasting blood glucose levels. The same pattern of response described for the first 3 patients is characteristic of the other 8 , as well.

The data presented for these 11 diabetic patients are consistent with the hypothesis that neither drug is intrinsically more effective than the other, and that the greater clinical efficacy of chlorpropamide, as compared with tolbutamide, is due to its longer metabolic half life. The longer metabolic half life (that is, the slower disappearance from the blood) enables the production of higher and more sustained serum sulfonylurea levels on a given dosage schedule. 
Knauff et al:: Chlorpropamide in Normals and Diabetics 615

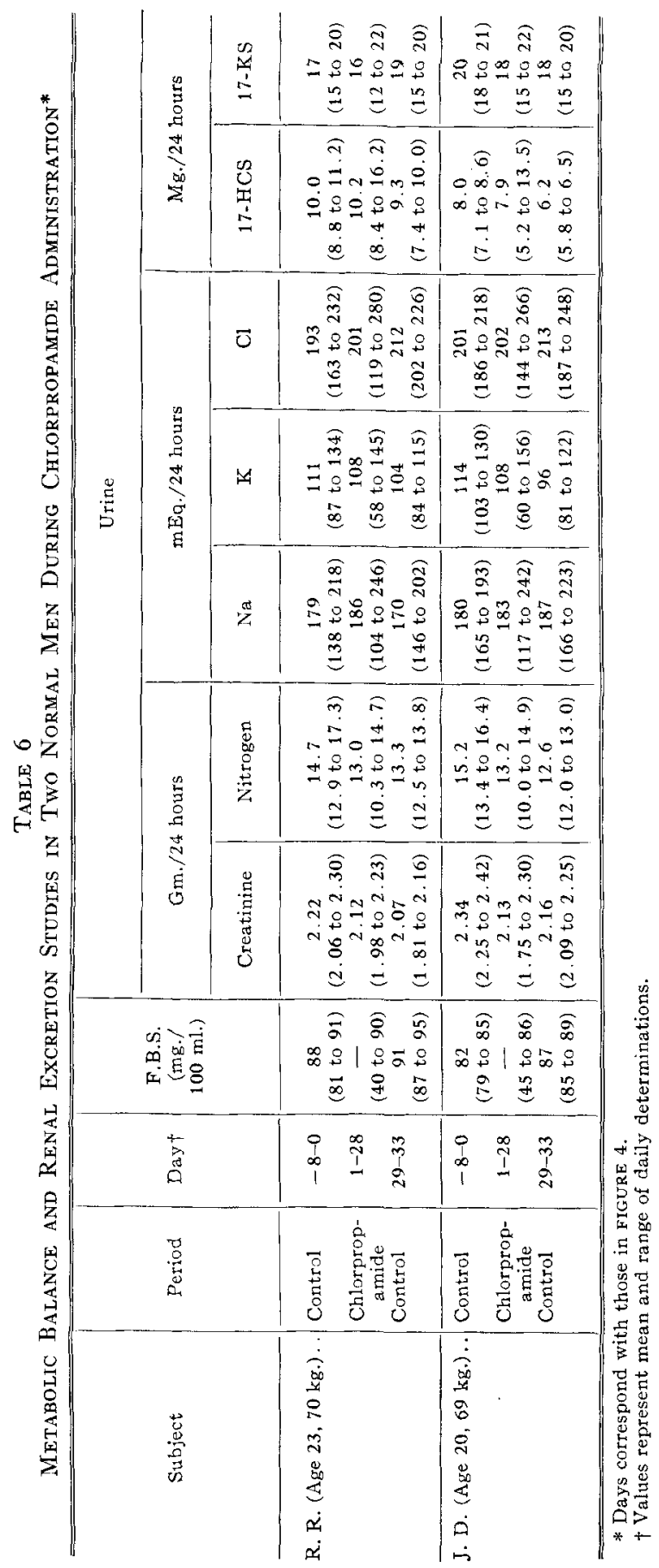


An example of the difference in response to the 2 drugs is illustrated in FIGURE 7.

Metabolic balance studies. Two normal men were studied for a period of about 4 weeks on an identical schedule of changing doses of chlorpropamide. The balance and renal excretion studies (TABLE 6) during chlorpropamide administration yielded results similar to those previously published from this laboratory for tolbutamide and carbutamide. ${ }^{6}$

There were no significant changes from control averages, for the mean urinary excretion of nitrogen, creatinine, electrolytes, 17 -hydroxycorticoids, and 17-ketosteroids, while on chlorpropamide. However, on several individual

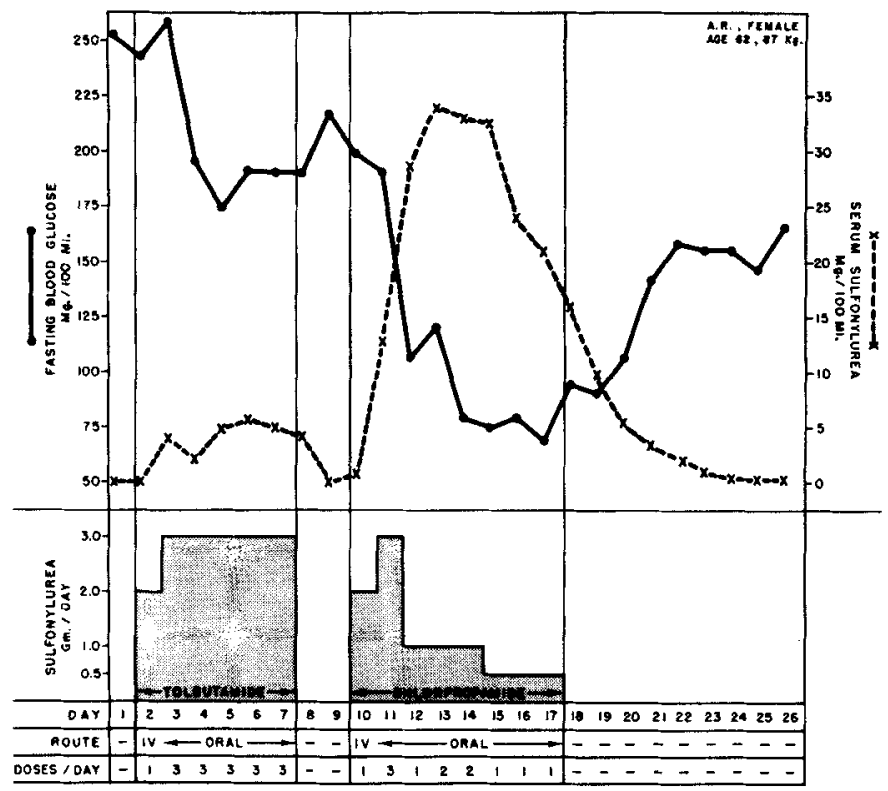

FIGURE 7. Fasting blood glucose and fasting serum sulfonylurea levels in a diabetic subject during the administration of tolbutamide and chlorpropamide.

days when severe symptomatic hypoglycemia had been produced, urinary excretion of nitrogen and electrolytes was significantly decreased, and the excretion of 17-hydroxycorticoids was increased. Serum levels of sodium, potassium, and chloride likewise were not affected.

\section{Summary and Conclusions}

(1) A single analytical method has been found to perform well for the determination of both chlorpropamide and tolbutamide in serum.

(2) Evidence has been presented from long-term studies to indicate that, on the basis of serum concentrations, chlorpropamide and tolbutamide are approximately equally active in normal men.

(3) Tolbutamide disappears from the blood of normal men and diabetic subjects approximately 8 times faster than does chlorpropamide. 


\section{Knauff et al.: Chlorpropamide in Normals and Diabetics 617}

(4) Chlorpropamide, when compared with tolbutamide on a weight basis, exhibits a markedly greater clinical effectiveness.

(5) The greater clinical efficacy observed with chlorpropamide seems adequately explainable on the basis of the capacity of the drug to produce and maintain higher serum levels on a given dosage schedule.

\section{References}

1. Forist, A. A., W. L. Miller, Jr, J. Krake \& W. A. Struck. 1957. Determination of plasma levels of tolbutamide. Proc. Soc. Exptl. Biol. Med. 96: 180.

2. Spingler, H. \& F. Kaiser. 1956. Die Bestimmung von N-(4-Methyl-benzolsulfonyl)$\mathrm{N}^{\prime}$-butyl-harnstoff in Serum. Arzneimittel-Forsch. 6: 760 .

3. Spingler, H. 1957. Über eine Möglichkeit zur colorimetrischen Bestimmung von N-(4-Methyl-benzolsulfony1)-N'-butyl-Harnstoff in Serum. Klin. Wochschr. 35: 533.

4. Bladi, E. \& A. Norden. 1958. A method for determining tolbutamide in human blood serum. Acta Pharmacol. Toxicol, 14: 188.

5. Louis, L. H., S. S. Fajans, J. W. Conn, W. A. Struck, J. B. Wright \& J. L. Johnson. 1956. The structure of a urinary excretion product of 1-butyl-3-p-tolylsulfonylurea. J. Am. Chem. Soc. 78: 5701 .

6. Fajans, S. S., L. H. Louis, H. S. Seltzer, R. D. Johnson, R. D. Gitiler, A. R. Hennes, B. L. Wajchenberg, I. P. Ackerman \& J. W. Conn. 1956. Metabolic effects of arylsulfonylurea compounds in normal men and in diabetic subjects. Metabolism. 5: 820 .

7. Wick, A. N., B. BritTon \& R. Grabowski. 1956. The action of Orinase in extrahepatic tissues. Metabolism. 5: 739. 